\title{
NATIONAL SURVEY TO EVALUATE MUSULOSKELETAL HEALTH IN RETIRED PROFESSIONAL BALLET DANCERS IN THE UNITED KINGDOM
}

\section{Authors:}

Dr Toby Smith - School of Health Sciences, University of East Anglia, UK

Dr Uche Oduoza - Emergency Medicine, Whittington Hospital, Whittington Hospital NHS Trust, London

Dr Akbar de Medici - Institute of Sports, Exercise and Health, University College London, London, UK

Dr Alan Hakim - Hypermobility Unit, Hospital of St John and St Elizabeth, London, UK

Dr Bruce Paton - Institute of Sports, Exercise and Health, University College London, London, UK Mr Greg Retter - Clinical Director, Ballet Healthcare, The Royal Ballet, London, UK

Prof Fares S Haddad - Institute of Sports, Exercise and Health, University College London, London, UK

Professor Alex Macgregor - Norwich Medical School, University of East Anglia, UK

Corresponding Author: Dr T Smith: Queen's Building, School of Health Sciences, University of East Anglia, Norwich Research Park, Norwich, NR4 7TJ. Email: toby.smith@uea.ac.uk; Telephone; 01603 593087; Fax: 01603593316 


\section{ABSTRACT}

Objectives: To explore the musculoskeletal health of retired professional ballet dancers in the United Kingdom (UK).

Design: Online national survey

Participants: Retired professional ballet dancers living in the UK.

Methods: The survey explored: what musculoskeletal injuries or diseases are experienced by retired professional ballet dancers; which anatomical regions were affected by musculoskeletal injuries or diseases in retired professional ballet dancers; whether ballet dancers were forced to retire from professional ballet due to musculoskeletal injuries or disease.

Results: Forty-six retired ballet dancers responded. Thirty-six percent $(n=17)$ of respondents reported retiring from ballet due to musculoskeletal injury. The median age when respondents retired from professional ballet was 29 years. The most common issues that caused people to retire were hip and back pain (25\%; $n=9$ respectively), followed by hamstring injuries, ankle injuries, cervical spine injuries, and anterior knee pain (13\% respectively; $n=5)$. Ninety-one percent $(n=42)$ reported experiencing muscle and joint pain post-retirement.

Conclusions: Musculoskeletal pain and disease was a problem for respondents in this study. Further investigation is needed to define the problem, so management can be examined. Comparing performance and training regimes to injury rates in professional dancers, and then following these cohorts into retirement, would increase knowledge on this population.

Keywords: ballet; long-term; risk factors; osteoarthritis 


\section{INTRODUCTION}

Professional ballet dancers are high performance, elite athletes who are at significant risk of musculoskeletal injury due to their training and performance requirements at extremes of joint capabilities (Jacobs, Cassidy, Cote, Boyle, Ramel, Ammendolia, Hartvigsen \& Schwartz, 2016). These individuals frequently experience musculoskeletal injuries particularly those which are overuse in nature (Jacobs et al.,2016; Bowerman, Whatman, Harris \& Bradshaw, 2015). Professional dancers undergo specialisation in technique and performance from an early age, with full-time engagement in dancing most frequently starting aged 15 years and over (Ekegren, Quested, \& Brodrick, 2014). A high level of activity at an adolescent growth spurt and stresses on the developing musculoskeletal system put ballet dancers at greater risk of growth-related overuse injuries, which can be a cause of longer-term chronic musculoskeletal injury and disease (American Academy of Pediatrics Committee of Sports Medicine and Fitness, 2000; Ekegren et al., 2014). Musculoskeletal diseases such as osteoarthritis, have been cited as potential causes of long-term disability and reduced quality of life for physically-active people (Pereira, Savero, Santos, Barros, Branco, Lucas, Costa \& Ramos, 2015). Previous studies have reported an association between engagement in physically-demanding activities such as football, netball and athletics, and the development of long-term musculoskeletal pain and disability (Siebenrock, Ferner, Noble, Santore, Werlen, \& Mamisch, 2011; Kapron et al., 2011). There is some, although limited, understanding on whether such an association is evident in recreational, semi-professional or professional ballet dancers.

The research team recently completed a systematic review of the evidence surrounding musculoskeletal injury profiles of retired and current professional ballet dancers (Smith, Davies, de Medici, Haddad, \& Macgregor, 2016). This reported that musculoskeletal injury has a significant burden on this population. These findings are in agreement with other reviews of musculoskeletal diseases in dancers (Smith, Gerrie, Varner, McCulloch, Litner \& Harris, 2015; Jacobs, Hincapie \& Cassidy, 2012; Hincapie, Morton \& Cassidy, 2008).

Previous studies have reported the injury profiles of professional ballet dancers (Ramkumar, Farber, Arnouk, Varner, Mcculloch, 2016; Costa, Ferreora, Orsini, Silva \& Felicio, 2016; Leanderson, Leanderson, Wykman, Strender, Johnansson \& Sundquist, 2011). Andersson, Nilsson, Hessel, Saraste, Noren, Stevens-Andersson \& Rydholm (1998), van Dijk, Lim, Poortman, Strübbe \& Marti (1995) and Einarsdottir, Troell \& Wykman (1995) reported data on Swedish and Dutch retired ballet dancers over 20 years ago. These cohorts presented with a greater prevalence of hallux valgus, foot and ankle osteoarthritis and joint hypermobility compared to matched cohorts of people who had not been professional ballet dancers. More recently Rönkkö, Heliövaara, Malmivaara, Roine, Seitsalo, Sainio \& Kettunen (2007) reported the findings of a survey of retired ballet dancers from the Finnish National 
Ballet company and the Union of Finnish Dance Artists. They reported that retired dancers were nearly three times more likely to experience chronic hip pain and nearly four times more likely to report chronic knee pain compared to an age-matched cohort of people who had not been professional ballet dancers.

The purpose of this study was to build on this previous knowledge, and to develop greater understanding of the musculoskeletal profiles of retired professional ballet dancers, specifically within the United Kingdom (UK) population. Therefore we conducted a national survey of retired professional ballet dancers in the UK, exploring the musculoskeletal profiles of this population. 


\section{METHODS}

\section{Participants}

Potential respondents were retired professional ballet dancers currently based in the UK. There were no specific age groups or a ratio of males to females targeted for recruitment. The term 'professional' was defined as someone who had been a previous member of a professional dance organisation and who had been employed as a ballet dancer at some point in their dancing careers. Whilst no data has been published on the number of retired professional ballet dancers living in the UK, it has been estimated that there are currently 262 professional ballet dancers performing in the UK, and a further 1198 professional or semi-professional dancers within the wider dance industry (DanceUK., 2015). As it was not possible to recruit from one source, as there is no single organisation which communicates with all retired professional ballet dancers in the UK, we recruited potential participants through a number of approaches. Firstly advertisements were posted on the Dance UK website (http://www.danceuk.org/healthier-dancer-programme/dance-medicine-and-scienceresearch/research-updates-and-opportunities/current/), the Healthier Dancer Programme Facebook pages, the British and International Federation for Festivals of Music, Dance and Speech (http://www.federationoffestivals.org.uk/), and the British Association for Performing Arts Medicine websites (http://www.bapam.org.uk/). A link to the survey was provided in each of the advertisements. Secondly the research team disseminated the study information through three Twitter accounts to provide a snowballing sampling strategy through re-tweets. Recruitment was open for eight weeks.

\section{Survey}

A self-administered online survey (through the SurveyMonkey platform (www.surveymonkey.com); Supplementary File 1) was developed to answer the following research questions: (1) what are the most frequent musculoskeletal injuries or diseases experienced by retired professional ballet dancers; (2) which are the most frequent anatomical regions affected by musculoskeletal injuries or diseases in retired professional ballet dancers; and (3) what is the proportion of surveyed ballet dancers who retire due to musculoskeletal injury or disease.

\section{Data Analysis}

Descriptive statistics and frequency distributions were used to collectively assess all completed surveys. The data were presented as frequency distributions and median values with inter-quartile ranges (IQR) 
where appropriate. All analyses were undertaken on Statistical Package for the Social Sciences (SPSS) version 18.0 (SPSS Inc, Chicago, Illinois).

\section{RESULTS}

Forty-six retired professional ballet dancers completed the online survey. The median age of respondents was 50 years (IQR: 42-56). The median age when respondents began profession ballet was reported as 16.5 years (IQR: 8-18). The median age when respondents retired from professional ballet was 29 years (IQR: 23-32.5). Twenty-four respondents reported their gender; this consisted of eight males and 14 females.

Thirty-six percent $(n=17)$ of respondents reported retiring from professional ballet due to musculoskeletal injury. Of this subgroup, the most common injuries which caused people to retire were hip and back pain ( $25 \%$ respectively; $n=9$ ), followed by hamstring injuries, ankle injuries, cervical spine injuries and anterior knee pain (12.5\% respectively; $\mathrm{n}=5)$.

Ninety-one percent $(n=42)$ of respondents reported experiencing muscle and joint pain post-retirement. Table 1 illustrates the anatomical regions reported to be currently or previously affected by pain. The most common regions included: lumbar spine $(71 \% ; n=32)$, knee $(53 \% ; n=24)$, hip $(53 \% ; n=24)$ and cervical spine $(41 \% ; n=19)$. Thirty percent of respondents reported a diagnosis of a muscle or joint condition by a healthcare professional. Conditions diagnosed were osteoarthritis $(80 \% ; n=37)$, hypermobility syndrome (20\%; $n=9)$, rheumatoid arthritis (20\%; $n=9)$ and tendinopathy $(20 \%$; $=9)$. Eight percent $(n=4)$ of these diagnoses were made once respondents had retired from professional ballet. Fifty-eight percent $(n=24)$ of respondents directly attributed their post-retirement muscle and joint pain to dancing at a professional level.

\section{DISCUSSION}

The findings of this survey indicate that musculoskeletal pain is a common problem for retired professional ballet dancers. The survey findings indicate that spinal and weight-bearing joints are most frequently affected, with osteoarthritis being the most predominant post-retirement musculoskeletal diagnosis.

These results indicate that people who retire from professional ballet dancing frequently attribute their muscle and joint pain to their profession. We did not explore what aspects of their professional career 
were associated with this belief. Previous studies have suggested strategies such as sprung and even floors, warmer studios and awareness of the need of active rest and training programmes specific to the musculoskeletal capabilities of dancers, may reduce musculoskeletal injury in this population (Bowling, 1989). Similarly factors such as training load, number of performances, age when commencing preprofessional and professional ballet and specific variables on the type of ballet performed may all influence injury incidence and profile (Askling, Lund, Saartok, \& Thorstensson, 2002). Awareness of such strategies has become more apparent in the past 20 years. Therefore assessing cohorts of dancers who were performing at the highest levels prior to this period, such as those previously reported by van Dijk et al. (1995), Einarsdóttir et al. (1995) and Andersson et al. (1989), may provide different results to our findings. Further investigation on what strategies may be related to musculoskeletal injury may provide useful insights into long-term injury prevention for future professional ballet dancers.

Whilst osteoarthritis was considered the most frequently diagnosed pathology amongst respondents, only $20 \%$ of respondents were diagnosed with hypermobility syndrome. This was lower than anticipated given that Briggs, McCormack, Hakim \& Grahame (2009) previously reported the prevalence of joint hypermobility, as assessed by skin hyper-extensibility and joint dislocation, as 33\% of females and 32\% of male professional dancers. It remains unclear whether, after retiring, joint hypermobility reduces in this population. The decline in joint hypermobility with age has been previously reported (Kwon, Lee, Park, Kim, Jang \& Choi, 2013) and may be attributed to the loss of collagen and cross-linking, leading to soft-tissue stiffness (Kirkendall \& Garrett, 1997). Further investigation is warranted to assess which joint pathologies develop after retiring in those with joint hypermobility (potentially a third of all dancers), whether this changes over time, and whether it is affected by factors such as injury, training, diet or age.

The most commonly presenting musculoskeletal pathologies in this cohort were hip and spinal pain, particularly lumbar spine. There are important findings as previous authors have acknowledge a potential relationship between elite sporting pursuits, hip and spinal pain and bone morphological changes, principally through the development of femoroacetabular impingement after performing at an elite sporting level (Kapron et al., 2011; Siebenrock et al., 2011). This may have been further amplified in our retired ballet cohort since there is a possible dose-response where repetitive loading (as performed in ballet) can further develop such morphological changes (Tak et al., 2015). Given the principal reason for retirement in this ballet cohort was hip and back pain, further research to better understand the relationship between specific sporting activities and morphological adaption is warranted.

Whilst these results provide insights that musculoskeletal pain and disease are problems in some retired ballet dancers, this study has a number of key limitations. Firstly, selection bias may have influenced the findings. The experience of musculoskeletal pain post-retirement may have influenced the recipients' interests towards completing the survey. Data which suggests selection bias may have 
occurred include the relatively low median age of the responding cohort (50 years) compared to the average age reported in other studies (van Dijk et al., 1995; Rönkkö et al., 2007). Nevertheless, the frequency of musculoskeletal symptoms, particularly in hip, knee and foot and ankle pathologies reported in our survey was high compared with those reported in the general population (Briggs, Cross, Hoy, Sanchez-Riera, Blyth, Woolf \& March, 2016). This is in agreement with the previous literature which suggests a higher probability of hip and knee pain of nearly three and four times greater respectively compared to age-matched non-retired dancers (Rönkkö et al, 2007). The results suggest a greater need for vigilance in this population. Further study to explore the implications and true prevalence of musculoskeletal diseases in this population would be valuable. The survey was only completed by 46 people. Accordingly, it remains unclear whether the responses were from a cohort who are typical of this population or a less representative, self-selecting sample. Finally, 20\% of respondents reported a diagnosis of rheumatoid arthritis which the researchers felt was unexpectedly high. This may be attributed to a misunderstanding regarding the diagnosis or nomenclature of rheumatoid arthritis compared to osteoarthritis, or that retired professional ballet dancers who have rheumatoid arthritis may experience more pain and disability and may therefore have been more willing to complete the survey, leading to response bias. Further exploration of a larger, longitudinal cohort would be of benefit to address these limitations.

\section{CONCLUSIONS}

This survey has reported the frequency of musculoskeletal disorders among professional ballet dancers in the UK. Although the group was difficult identify, with a relatively low response rate, our findings suggest that musculoskeletal pain, particularly in the lower limbs and spine, may be associated with significant continuing symptoms in this population. Further research is required to define the problem, before any consideration can be made about management and prevention. Investigation is warranted to analyse the performance and training regimes of professional ballet dancers in comparison to injury rates, and then to follow such a cohort longitudinally into their retirement. This would provide important epidemiological data, facilitating increased knowledge on the musculoskeletal profile of this population.

\section{FIGURE AND TABLE LEGENDS}


Table 1: Reported anatomical regions currently or previously affected by musculoskeletal symptoms and musculoskeletal diagnoses reported by respondents $(n=46)$.

Supplementary File 1: Survey

\section{HIGHLIGHTS}

- Musculoskeletal disorders are a challenge for retired professional ballet dancers.

- $91 \%$ of this study's cohort have experienced musculoskeletal pain and symptoms.

- $36 \%$ of this cohort retired from professional ballet due to musculoskeletal injury.

- Common anatomical regions affected include the lumbar spine, knee, hip and neck. 


\section{ETHICAL STATEMENT/APPROVAL}

Ethical approval: Ethical approval was gained from the University of East Anglia Research Ethics Committee (Reference number: 20142015-49).

\section{ACKNOWLEDGEMENTS}

Ethical approval: Ethical approval was gained from the University of East Anglia Research Ethics Committee (Reference number: 20142015-49).

Funding: No funding was received to undertake this work.

Author Contributions: TS and AM conceived the study; TS, AM AdM, AH and FSH designed the survey; TS and UO recruited and gathered the data; all authors interpreted the data; all authors prepared the manuscript; all authors approved the final manuscript.

Conflicts of Interest: The authors declare no conflicts of interest in relation to this work. 


\section{CONFLICT OF INTEREST STATEMENT}

Title: National survey to evaluate musculoskeletal health with retired ballet dancers in the United Kingdom.

\section{Authors:}

Dr Toby Smith - School of Health Sciences, University of East Anglia, UK

Dr Uche Oduoza - Emergency Medicine, Whittington Hospital, Whittington Hospital NHS Trust, London

Dr Akbar de Medici - Institute of Sports, Exercise and Health, University College London, London, UK

Dr Alan Hakim - Hypermobility Unit, Hospital of St John and St Elizabeth, London, UK

Dr Bruce Paton - Institute of Sports, Exercise and Health, University College London, London, UK

Mr Greg Retter - Clinical Director, Ballet Healthcare, The Royal Ballet, London, UK

Prof Fares S Haddad - Institute of Sports, Exercise and Health, University College London, London, UK

Professor Alex Macgregor - Norwich Medical School, University of East Anglia, UK

Conflict of Interests: None declared. 


\section{REFERENCES}

1. Jacobs CL, Cassidy JD, Côté P, et al. Musculoskeletal injury in professional dancers: prevalence and associated factors: an international cross-sectional study. Clin J Sport Med 2016; In Press.

2. Bowerman EA, Whatman C, Harris N, Bradshaw E. A review of the risk factors for lower extremity overuse injuries in young elite female ballet dancers. J Dance Med Sci. 2015;19:51-6.

3. Ekegren CL, Quested R, Brodrick A. Injuries in pre-professional ballet dancers: Incidence, characteristics and consequences. J Sci Med Sport 2014;17:271-75.

4. American Academy of Pediatrics Committee of Sports Medicine and Fitness. Intensive training and sports specialization in young athletes. Pediatr 2000;106:156-57.

5. Pereira D, Severo M, Santos RA, et al. Knee and hip radiographic osteoarthritis features: differences on pain, function and quality of life. Clin Rheumatol 2015; In Press.

6. Siebenrock KA, Ferner F, Noble PC, Santore RF, Werlen S, Mamisch TC. The cam type deformity of the proximal femur arises in childhood in response to vigorous sporting activity. Clin Orthop Relat Res 2011;469:3229-40.

7. Kapron AL, Anderson AI, Aoki SK, et al. Radiographic prevalence of femoroacetabular impingement in collegiate football players: AAOS Exhibit Selection. J Bone Joint Surg Am 2011;93:e111(1-10).

8. Smith TO, Davies L, de Medici A, Haddad F, Macgregor A. The prevalence and injury profile of musculoskeletal injuries in ballet? A systematic review and meta-analysis. Phys Ther Sport 2016; 19:50-6..

9. Smith PJ, Gerrie BJ, Varner KE, McCulloch PC, Lintner DM, Harris JD. Incidence and prevalence of musculoskeletal injury in ballet: a systematic review. Orthop J Sports Med 2015; In Press.

10. Jacobs CL, Hincapié CA, Cassidy JD. Musculoskeletal injuries and pain in dancers: a systematic review update. J Dance Med Sci 2012;16:74-84.

11. Hincapié CA, Morton EJ, Cassidy JD. Musculoskeletal injuries and pain in dancers: a systematic review. Arch Phys Med Rehabil 2008;89:1819-29. 
12. Ramkumar PN, Farber J, Arnouk J, Varner KE, Mcculloch PC. Injuries in a professional ballet dance company: a 10-year retrospective study. J Dance Med Sci 2016;20:30-7.

13. Costa MS, Ferreira AS, Orsini M, Silva EB, Felicio LR. Characteristics and prevalence of musculoskeletal injury in professional and non-professional ballet dancers. Braz J Phys Ther 2016; In Press.

14. Leanderson C, Leanderson J, Wykman A, Strender LE, Johansson SE, Sundquist K. Musculoskeletal injuries in young ballet dancers. Knee Surg Sports Traumatol Arthrosc 2011; 19:15315.

15. Andersson S, Nilsson B, Hessel T, Saraste M, Noren A, Stevens-Andersson A, Rydholm D. Degenerative joint disease in ballet dancers. Clin Orthop Relat Res 1989; 238:233-6.

16. van Dijk CN, Lim LS, Poortman A, Strübbe EH, Marti RK. Degenerative joint disease in female ballet dancers. Am J Sports Med 1995; 23:295-300.

17. Einarsdóttir H, Troell S, Wykman A. Hallux valgus in ballet dancers: a myth? Foot Ankle Int $1995 ; 16: 92-4$.

18. Rönkkö R, Heliövaara M, Malmivaara A, Roine R, Seitsalo S, Sainio P, Kettunen J. Musculoskeletal pain, disability and quality of life among retired dancers. J Dance Med Sci 2007; 11:105-9.

19. DanceUK. Things you should know about dance. Accessed: 30.03.2015. Available at: https://www.danceuk.org/resources/dance-facts/

20. Bowling A. Injuries to dancers: prevalence, treatment, and perceptions of causes. BMJ $1989 ; 298: 731-4$.

21. Askling C, Lund H, Saartok T, Thorstensson A. Self-reported hamstring injuries in studentdancers. Scand J Med Sci Sports 2002;12:230-5.

22. Briggs J, McCormack M, Hakim AJ, Grahame R. Injury and joint hypermobility syndrome in ballet dancers--a 5-year follow-up. Rheumatology 2009;48:1613-4.

23. Kwon JW, Lee WJ, Park SB, Kim MJ, Jang SH, Choi CK. Generalized joint hypermobility in healthy female koreans: prevalence and age-related differences. Ann Rehabil Med 2013;37:832-8. 
24. Kirkendall DT, Garrett WE. Function and biomechanics of tendons. Scand J Med Sci Sports 1997;7:62-6.

25. Tak I, Weir A, Langhout R, et al. The relationship between the frequency of football practice during skeletal growth and the presence of a cam deformity in adult elite football players. Br J Sports Med 2015;49:630-34.

26. Briggs AM, Cross MJ, Hoy DG, et al. Musculoskeletal health conditions represent a global threat to healthy aging: a report for the 2015 World Health Organization world report on ageing and health. Gerontologist 2016;56 Suppl 2:S243-55. 
Table 1: Reported anatomical regions currently or previously affected by musculoskeletal symptoms and musculoskeletal diagnoses reported by respondents $(n=46)$.

\begin{tabular}{l|l|c}
\hline \multirow{2}{*}{$\begin{array}{l}\text { Anatomical regions most affected by } \\
\text { muscle and joint pain }\end{array}$} & Hip & Frequency (\%) \\
\cline { 2 - 3 } & Knee & $24(53)$ \\
\cline { 2 - 3 } & Feet & $24(53)$ \\
\cline { 2 - 3 } & Toes & $16(35)$ \\
\cline { 2 - 3 } & Low back & $8(18)$ \\
\cline { 2 - 3 } & Mid-back & $32(71)$ \\
\cline { 2 - 3 } & Neck & $14(29)$ \\
\cline { 2 - 3 } & Shoulder & $19(41)$ \\
\cline { 2 - 3 } & Elbow & $14(29)$ \\
\cline { 2 - 3 } & Forearm & $3(6)$ \\
\cline { 2 - 3 } & Wrist & $3(6)$ \\
\cline { 2 - 3 } & Hands & $3(12)$ \\
\hline \multirow{4}{*}{ What conditions have been diagnosed? } & Osteoarthritis & $9(20)$ \\
\cline { 2 - 3 } & Hypermobility syndrome & $0(0)$ \\
\cline { 2 - 3 } & Fibromyalgia & $9(20)$ \\
\cline { 2 - 3 } & Spinal disc prolapse (slipped disc) & $9(20)$ \\
\cline { 2 - 3 } & Rheumatoid Arthritis & $37(0)$ \\
\cline { 2 - 3 } & Tendinopathy or tendinitis & 9 \\
\hline
\end{tabular}


Supplementary File 1: Survey

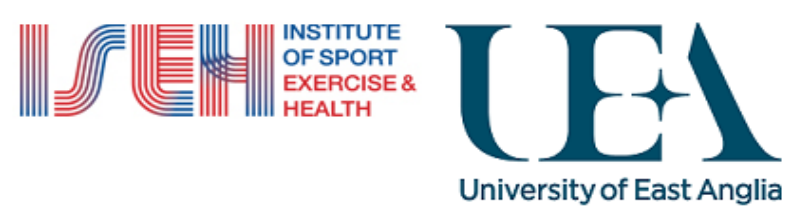

UK survey of muscle and joint health in retired professional ballet dancers

UK survey of muscle and joint health in retired professional ballet dancers

Thank you for considering to do our survey on the health of retired professional ballet dancers muscles and joints. This survey will help us to gain a nationwide picture of current experiences of retired professional ballet dancer's muscle and joint care which may help develop future research in this area

The initial questions will confirm that you agree to complete the survey and for the responses to be used anonymously and confidentially. Throughout this survey, we will not be able to identify you from the responses you provide (anonymity) and all data will be stored confidentially at the University of East Anglia.

The survey will take no longer than 10 minutes to complete. You will be unable to save and re-join the survey so please complete the survey in one go. Only once you have completed the survey will your responses be saved and used in the analysis.

Can you please only complete the survey once. Please tell other retired professional ballet dancers living in the UK about the survey as we want to gain as many views and experiences as possible.

If you have any questions, please feel free to contact the lead researcher (Dr Toby Smith) by email (toby.smith@uea.ac.uk) or by telephone (01603 593087).

Thank you for your time.

Toby

* 1. Are you a retired professional ballet dancer who currently lives in the United Kingdom?

$\square$ Yes

$\square$ No 


\section{IF YES TO QUESTION 1....}

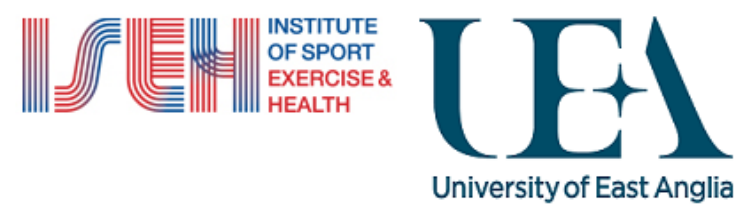

UK survey of muscle and joint health in retired professional ballet dancers

Consent Question 2

* 2. Do you understand that the responses you provide in this survey will be confidential and anonymised so you will not be identifiable in the public domain. $\square$ Yes

T No 


\section{||W|| \\ University of East Anglia}

UK survey of muscle and joint health in retired professional ballet dancers

Consent 3

* 3. Do you agree that the responses you provide when you complete and submit this survey can be analysed and reported in a research report?

प Yes

No 
IF NO TO QUESTIONS 1, 2 OR 3.....

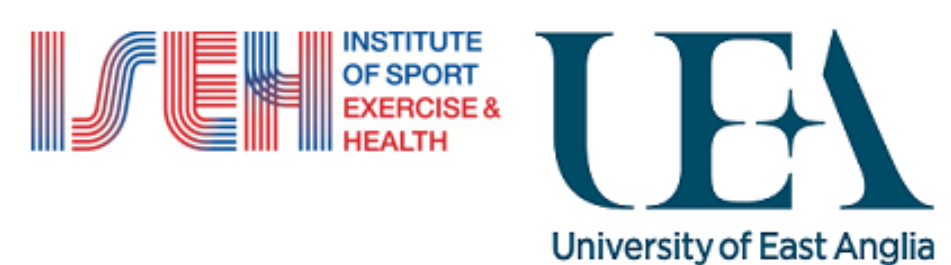

UK survey of muscle and joint health in retired professional ballet dancers

Thank you for your assistance

2. Thank you for your time in considering to complete this survey, but you will not be required to continue.

IF YES TO QUESTIONS 1,2,3... 


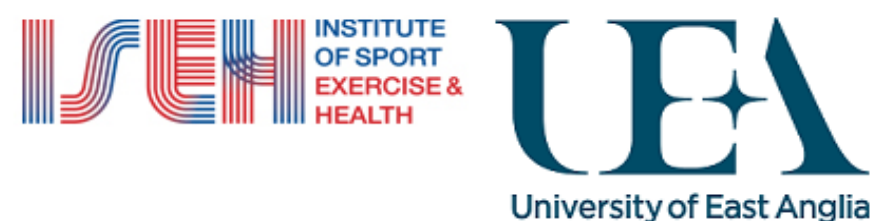

UK survey of muscle and joint health in retired professional ballet dancers

Respondent Characteristics

\section{* 4. How old are you currently?}

\section{* 5. Are you male or female?}

$\square$ Male

$\square$ Female

\section{* 6. What part of the UK do you live in?}
$\square$ London
$\square$ East of England
$\square$ South East
$\square$ South West
$\square$ Midlands/Central
North West
$\square$ North East
$\square$ Scotland
$\square$ Wales 
* 7. How old were you when you began professional ballet?

* 8 . How old were you when you retired from professional ballet?

* 9. Did you retired from professional ballet due to injury, and if so, what type of injury?

$\square$ Yes

No

Type of Injury 


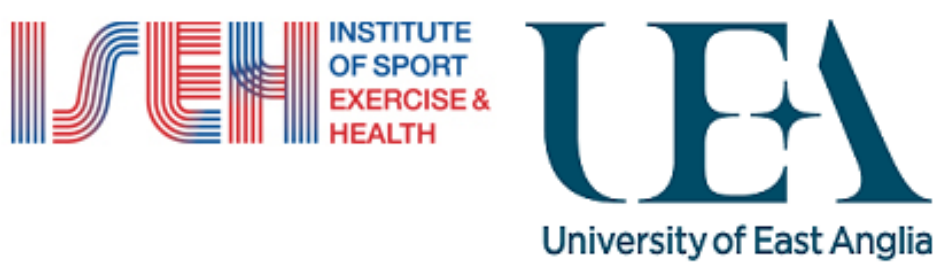

UK survey of muscle and joint health in retired professional ballet dancers

Post-retirement muscle or joint pain?

* 10. Have you experienced muscle or joint pain since retiring from professional ballet?

$\square$ Yes

$\square$ No

* 11. Are you currently (in the past 7 days) experiencing muscle or joint pain?

Yes

$\square$ No

IF EITHER ARE NO...JUMPS TO QUESTION 17.

IF 10 or 11 ARE YES...JUMPS TO QUESTION 12. 


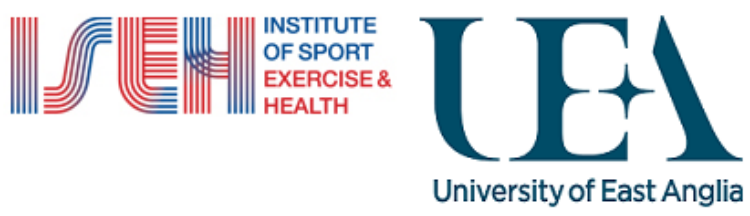

UK survey of muscle and joint health in retired professional ballet dancers

* 12. What parts of your body are or have been most frequently affected by muscle or joint pain? (tick all which apply)
Hip
W Knee
W Feet
[ Toes
L Low back
Mid-back
ए Neck
W Shoulder
$\square$ Elbow
$\square$ Forearm
$\square$ Wrist
$\square$ Hands

Additional comments

* 13. Have you been diagnosed with a muscle or joint disease or condition by a healthcare professional?

Yes

$\square$ No

Additional comments 


\section{IIIII) \\ University of East Anglia}

UK survey of muscle and joint health in retired professional ballet dancers

* 14. What conditions were these? (tick all which apply)

Osteoarthritis

$\square$ Hypermobility syndrome

- Fibromyalgia

$\square$ Spinal disc prolapse (slipped disc)

$\square$ Rheumatoid Arthritis

$\square$ Tendinopathy or tendinitis

Other (please specify)

* 15. Were you diagnosed with this before or after you retired from professional ballet?

$\square$ Before

$\square$ After

$\square$ Unsure

Additional comments

* 16. Do you attribute your muscle or joint pain since retiring from professional ballet, to ballet or dance?

$\square$ Yes

No

Additional comments 


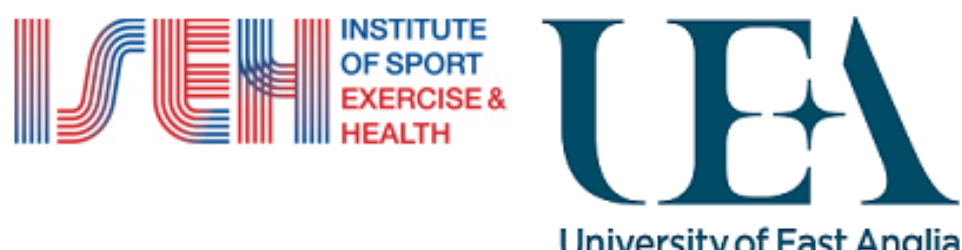

University of East Anglia

UK survey of muscle and joint health in retired professional ballet dancers

Final questions

* 17. Do you still dance (non-professionally)?

ए Yes

$\square$ No

Additional comments

* 18. Would you be interested in participating in future research on joint or muscle health in retired professional ballet dancers?

ए Yes

$\square$ No

I would be interested in further information before making a decision

Additional comments 
IF QUESTION 18 IS YES...JUMPS TO QUESTION 17 followed by 18

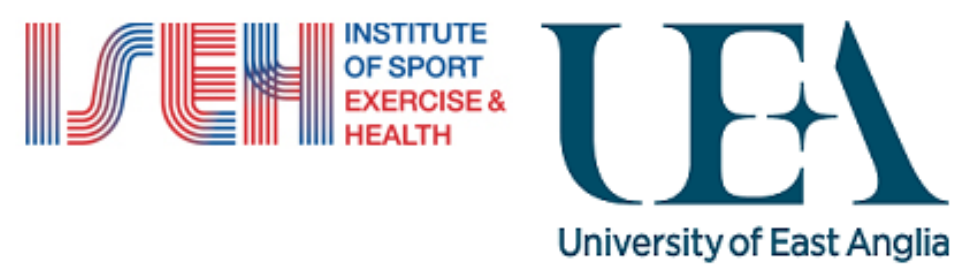

UK survey of muscle and joint health in retired professional ballet dancers

19. Please provide your email address and we will provide you with more information on this.

This email address will not be shared with any other organisations or groups within or external to the University of East Anglia. 


\section{IIIII}

UK survey of muscle and joint health in retired professional ballet dancers

Thank you for completing this survey

20. Thank you for completing this survey. If you would like to receive a copy of the final report, please email the lead researcher (toby.smith@uea.ac.uk) who will send this to you once it is completed.

Many thanks. Toby

Prev Done 
IF QUESTION 18 IS NO....

\section{"IIU OF SPORT EXERCISE \&
HEALTH \\ University of East Anglia}

UK survey of muscle and joint health in retired professional ballet dancers

Thank you for completing this survey

19. Thank you for completing this survey. If you would like to receive a copy of the final report, please email the lead researcher (toby.smith@uea.ac.uk) who will send this to you once it is completed.

Many thanks. Toby 